Revista de Ciencias Sociales - Número 63 (2013) - Páginas 145-167

Derecho del trabajo y derechos fundamentales: ciudadanía en la empresa

\title{
DERECHO DEL TRABAJO Y DERECHOS FUNDAMENTALES: CIUDADANÍA EN LA EMPRESA
}

\author{
LABOUR LAW AND FUNDAMENTAL RIGHTS: \\ CITIZENSHIP IN THE COMPANY
}

ERICK LAYANA VENENCIANO*

Pontificia Universidad Católica de Valparaíso

layana.erick@gmail.com

\section{Resumen}

Nuestro derecho ha reconocido la horizontalidad de los derechos fundamentales entre particulares. Al respecto la teoría de la horizontalidad cumple un papel fundamental en las relaciones laborales, pues los poderes que ostenta el empleador, deben ser limitados por el respeto y vigencia plena de los derechos fundamentales inespecíficos del trabajador. Es así como la Dirección de Trabajo, en un comienzo, y el legislador laboral después, reconocen que el trabajador no pierde bajo ninguna circunstancia sus derechos fundamentales, ya que es ciudadano tanto dentro como fuera de la empresa. Este trabajo pretende dar una mirada general a la teoría de la horizontalidad de los derechos fundamentales en el plano laboral, analizando los conceptos que se manejan al respecto, la jurisprudencia de la Dirección del Trabajo, y las modificaciones legales que han venido a reconocer expresamente lo que la doctrina laboralista ha llamado: Ciudadanía en la Empresa.

* Estudiante de Derecho, Escuela de Derecho de la Pontificia Universidad Católica de Valparaíso. Valparaíso, Chile. Artículo recibido el 5 de noviembre de 2013 y aceptado el 2 de diciembre de 2013.

Revista de Ciencias Sociales - Número 63 (2013) - Universidad de Valparáíso - ISSN 0716-7725-Valparaíso, Chile 


\title{
Palabras claves
}

Derechos fundamentales, trabajador, empresa.

\begin{abstract}
Our Law has recognized the horizontal effects of the fundamental rights between individuals. In the matter, the theory of the horizontal effect fulfills a fundamental role in the working relationships, since the power that the employer shows must be limited for the respect and the full force of the fundamental unspecific rights of the worker. It is as well as the Direction of Work, in a beginning, and the labour law later, admit that the workers don't lose under any circunstances their fundamental rights, because they are citizens both inside and outside the company. This paper tries to give a general sight about the theory of the horizontal effects of fundamental rights in the labour area, analyzing the concepts that are handled in the subject, the jurisprudence of the Direction and the legal modifications that have come to recognize expressly what the labour doctrine has called: Corporated Citizenship.
\end{abstract}

\section{Keywords}

Fundamental rights, worker, company.

\section{Introducción}

Podemos situar el nacimiento del derecho del trabajo a partir de la Revolución Industrial: es en este momento histórico donde las personas comienzan a trabajar poniendo su esfuerzo y, en cierto sentido, su propia libertad a disposición de su patrón. Con la Revolución el trabajo toma vital importancia, pues pasa a ser un trabajo productivo que permite a hombres y mujeres —en condiciones deplorablessatisfacer sus necesidades. Así, comienza el progresivo desarrollo de la industria como fuente principal de trabajo, pues la fábrica necesitaba mano de obra y las personas necesitaban comer. Muchos vieron acá la posibilidad de nuevas oportunidades de vida, ya que ahora recibirían a cambio de su trabajo, dinero. En consecuencia, comienza una paulatina masificación del trabajo asalariado, dejando la lógica del feudalismo atrás.

Facultad de Derecho y Ciencias Sociales - Universidad de Valparaíso - Chile 
En el panorama de la época teníamos al patrón y al obrero: el primero necesitaba de trabajo y el segundo necesitaba trabajar, con lo que comienza entonces a generarse una relación jurídica de prestación de servicios (trabajador) y el pago de dinero por aquellos (patrón). Ergo, podemos observar que se fueron creando - no exento de problemaslos primeros "contratos de trabajo", pero ¿cómo se resolvían los problemas derivados de estos si no había una regulación especial?

La respuesta fácil fue entregar la solución al derecho civil; sin embargo este no fue capaz de frenar los abusos que se producían, ni de resolver los problemas laborales, pues estaba - y sigue siendo asíestructurado bajo dos dogmas, considerados burgueses en la época y que no existen en materia laboral: igualdad jurídica y libertad contractual. Por lo tanto, el derecho civil en alguna medida permitió que se cometieran abusos hacia los trabajadores. Con este triste panorama y con el reclamo de los primeros grupos organizados de trabajadores, y con el miedo de los empleadores a perder sus cuotas de poder, surgen las primeras leyes laborales, como decía, no por la preocupación de los dueños de las fábricas por los hombres, mujeres y niños que ahí trabajaban, sino por el miedo a que se levantara una verdadera revolución del proletariado.

Con todo, la legislación laboral se preocupa de un especial tipo trabajo: el trabajo subordinado. Con el desarrollo de la legislación laboral, no se debe hablar ya de patrón ni de obrero, sino de empleador y trabajador respectivamente, relación en que existe una especial subordinación. La subordinación por lo tanto, es el elemento central del derecho del trabajo, como dice el profesor Ugarte, "en el origen de la legislación social —antecedente inmediato del Derecho del Trabajo-no aparece nada ni en las normas ni en los que hablan sobre las normas que se llame subordinación o dependencia jurídica. Legislación de emergencia dictada bajo fuertes impulsos políticos no se construye bajo ninguna racionalidad dogmática, sino como respuesta a las condiciones económicas de miseria a que da lugar la segunda revolución industrial, intentando mejorar a específicos grupos de trabajadores - mujeres, menores o accidentados - que sólo tienen en común la explotación de la que son objeto.

Así se pregunta Ugarte: ¿Cómo llega, en ese escenario, la subordinación a transformarse en la noción cardinal del Derecho del Trabajo?

Revista de Ciencias Sociales - Número 63 (2013) - Universidad de Valparáíso - ISSN 0716-7725-Valparaíso, Chile 
La respuesta es sencilla: no llega, sino que nace con el Derecho del Trabajo"1.

Con todo, la subordinación es una categoría jurídica, que ha sido construida por el derecho como un elemento diferenciador. Supiot nos dice que es "la relación en que uno puede mandar y el otro ha de obedecer. Es decir: que la cuestión del poder se halla en el corazón mismo del derecho del trabajo"n. La subordinación da cuenta de una especial forma de trabajar, en la cual el trabajador se encuentra en la necesidad jurídica de tener que desarrollar su prestación de servicios, conforme a las órdenes e instrucciones que le da el empleador, en lo que tiene relación con el tiempo, lugar y forma.

¿Qué ocurre? La subordinación genera el siguiente efecto: dos particulares celebran un contrato, que generará efectos jurídicos para ellos, pero que también generará una relación vertical entre el trabajador y el empleador. Existe un poder de control y dirección muy potente mirado desde la óptica del empleador, y una relación de subordinación desde la perspectiva del trabajador, y que no se da en ningún otro ámbito de la relación entre particulares. El trabajador queda en una situación de inferioridad respecto del empleador. Así se trata de una moneda de dos caras: cuando se mira desde la perspectiva del trabajador hablamos de subordinación. Si la miramos desde la perspectiva del empleador, a este se le reconoce un poder de dirección y control.

En este contexto es que se producen los abusos por parte del fuerte - empleador - contra el débil — trabajador - y es tarea del Derecho del Trabajo hacer frente a tales abusos. En esta línea la doctrina y la jurisprudencia han venido desarrollando la idea de "Ciudadanía en la Empresa", que apunta a niveles más exigentes que los derechos laborales propiamente tales, pues atiende también a los derechos que tienen los trabajadores por el solo hecho de ser ciudadanos. Una de las evoluciones más interesante que se ha planteado en el área laboral es el

1. UGARTE CATALDO, José Luis. El nuevo Derecho del Trabajo. LexisNexis, Santiago, 2007. Pág. 21.

2. SUPIOT, Alain. Crítica del derecho del trabajo. Ministerio del Trabajo y Asuntos Sociales, Madrid, 1996. Pág. 133.

Facultad de Derecho y Ciencias Sociales - Universidad de Valparaíso - Chile 
desarrollo de este concepto que se preocupa y ocupa de la vigencia, promoción y respeto de los derechos fundamentales de los trabajadores en sus lugares de trabajo, principio a mi entender, base de cualquier Estado Democrático de Derecho.

Se trata de un tema nuevo, pues como dice el profesor Gamonal: "Sólo durante los últimos quince años la doctrina laboral ha estudiado los derechos laborales inespecíficos (terminología del profesor Palomeque), cuya proyección al interior de las relaciones de trabajo es de gran importancia si consideramos que la relación de trabajo más que un vínculo de coordinación entre pares, es un vínculo de subordinación, sumisión, en fin, una relación de poder de un sujeto privado sobre otro"”.

En este sentido el profesor Caamaño es claro: "El Derecho del Trabajo contemporáneo ha experimentado una notoria evolución dogmática jurídica en el último tiempo, lo que, en gran medida, ha tenido lugar a partir de la explicitación del reconocimiento del trabajador como titular de derechos que emanan de su propia esencia como ser humano y que, en tal carácter, se proyectan naturalmente en el ejercicio de su actividad laboral y, en concreto, en la empresa, como ámbito específico en el que éste presta sus servicios".

A continuación, me he propuesto desarrollar la noción de Ciudadanía en la Empresa con que la doctrina trabaja, como también analizar la concreción positiva de esta novedosa idea en el derecho nacional. Terminaré con algunas reflexiones que ayuden al debate jurídico y político, con el objeto de materializar este concepto y que no solo se quede en buenas intenciones.

3. GAMONAL CONTRERAS, Sergio. Ciudadanía en la Empresa o Derechos Fundamentales Inespecíficos. Fundación de la Cultura Universitaria, Santiago, 2004. Pág. 14.

4. CAAMAÑO ROJO, Eduardo. "La eficacia de los derechos fundamentales en las relaciones laborales y su reconocimiento por la Dirección del Trabajo”. En: Revista de Derecho de la Pontificia Universidad Católica de Valparaíso, N 27 (I semestre), 2006. Pág. 20.

Revista de Ciencias Sociales - Número 63 (2013) - Universidad de Valparáíso - ISSN 0716-7725-Valparáiso, Chile 
2. Conceptualización de la Ciudadanía en la Empresa: no fue amor a primera vista

\subsection{Origen}

Como he anunciado de manera general en los párrafos anteriores, la jurisprudencia y la legislación han desarrollado esta noción aceptando la teoría de la horizontalidad de los derechos fundamentales, recogiendo lo que en los años cincuenta la jurisprudencia alemana llamó la eficacia directa de los derechos fundamentales entre particulares (los alemanes lo llamaron teoría de la "Drittwirkung der Grundrechte" u "Horizon talwirkung"). Así se abandona la tradicional idea de que los derechos fundamentales sólo podían ser invocados como un "mecanismo de defensa" frente a los abusos en que podía incurrir el Estado, por lo que la vulneración de derechos fundamentales entre particulares era mirada con cierto rechazo o recelo, y así lo hacía este autor en un comienzo.

Mi posición inicial se vio afectada al estudiar en sede procesal civil lo que la doctrina procesalista denomina prueba ilícita. La prueba ilícita surge históricamente en la jurisprudencia de la Corte Suprema de Estados Unidos para excluir del proceso penal las pruebas obtenidas por agentes del Estado vulnerando alguna norma, especial y fundamentalmente, vulnerando garantías constitucionales. En el proceso penal no hay duda de que se debe rechazar categóricamente el ofrecimiento y/o producción de pruebas violando derechos fundamentales, pues es el Estado, a través del órgano persecutor, el que lo hace, pero ¿se puede sostener lo mismo en el proceso civil?

En mi opinión creer que se vulneran derechos fundamentales entre particulares en sede civil es una locura, por lo que si se obtiene una prueba vulnerando la privacidad de una parte, por ejemplo, esa prueba debe admitirse y ser valorada en el proceso, y si existe una afectación, esta debe reclamarse en otro procedimiento. Así, en este ámbito sigo la doctrina clásica y sostengo que sólo el Estado y sus agentes pueden vulnerar derechos fundamentales.

Teniendo presente lo expuesto sucintamente en líneas precedentes, al enfrentarnos a una relación laboral debemos cambiar la

Facultad de Derecho y Ciencias Sociales - Universidad de Valparaíso - Chile 
óptica con que miramos el tema, pues la relación empleador-trabajador no se da en un plano de igualdad, ya que hay una asimetría fáctica tanto jurídica como económica. En este esquema se producen abusos hacia el trabajador que pueden llegar a vulnerar los derechos fundamentales de este último.

Además, tal como expresa Ugarte, "en este sentido, Chile corresponde a un caso de eficacia directa y horizontal de los derechos fundamentales en las relaciones entre particulares, con vigencia inmediata, donde el lesionado puede recurrir a la jurisdicción constitucional en busca de amparo en sus derechos fundamentales contra actos de terceros" ${ }^{\prime \prime}$. Esto se refuerza al revisar el artículo 6, inciso segundo de la Constitución Política de 1980, donde se establece que los preceptos de esta Constitución obligan tanto a los titulares o integrantes de dichos órganos (del Estado) como a toda persona, institución o grupo. Ergo, los derechos y garantías reconocidos en la Constitución Política de 1980, no sólo son exigibles a los órganos públicos y estatales, sino que también se pueden exigir directamente respecto a terceros particulares. En este mismo sentido conviene mencionar el artículo 20 del texto constitucional al consagrar el conocido recurso de protección para reclamar las acciones $\mathrm{u}$ omisiones arbitrarias o ilegales que priven, perturben o amenacen el ejercicio legítimo de los derechos y garantías que reconoce el artículo número 19, según la numeración contenida en el artículo 20.

Por lo tanto, la teoría que surgió en la jurisprudencia alemana en los años cincuenta, cuando el Tribunal Laboral Federal anula una cláusula de un contrato de trabajo por vulnerar derechos fundamentales, reconociendo así lo que posteriormente se conocería como teoría de la horizontalidad de los derechos fundamentales, es el antecedente directo del origen de la Ciudadanía en la Empresa.

\section{2. ¿Existe tal horizontalidad?}

Como se ha expuesto, durante el siglo XX la verticalidad de los derechos fundamentales, es decir, la relación Estado-ciudadano, fue complementada con la horizontalidad de los derechos en una relación

5. UGARTE CATALDO, José Luis. Ob. cit. Pág. 121.

Revista de Ciencias Sociales - Número 63 (2013) - Universidad de Valparaíso - ISSN 0716-7725-Valparaíso, Chile 
ciudadano-ciudadano, reconociendo la eficacia directa de los derechos fundamentales entre particulares.

Podemos decir con seguridad que para el derecho laboral no hay dudas respecto a que el trabajador goza con toda plenitud de derechos fundamentales por el sólo hecho de ser ciudadano tanto fuera como dentro de la organización empresarial. Así la jurisprudencia, la doctrina y también el legislador, han aceptado y reconocido con entusiasmo la eficacia horizontal de los derechos fundamentales en las relaciones laborales, pero hay una pregunta que nos debemos hacer: ¿hay realmente horizontalidad?

La pregunta anterior admite al menos dos matices: primero, ¿̇se pueden vulnerar entre particulares derechos fundamentales? Creo que la respuesta es más o menos clara, y no es necesario repetir lo señalado en el apartado anterior. No obstante, debemos tener presente que aún se sostiene por parte importante de la doctrina que los derechos fundamentales sólo tienen vigencia en una relación ciudadano-Estado. Es más, los civilistas ven con sospecha y recelo la teoría de la horizontalidad, pues vendría a limitar excesivamente lo que ellos consideran su bien jurídico superior: la autonomía de la voluntad.

Sin embargo, debemos recordar que en el derecho laboral, ese dogma civilista prácticamente no rige, pues como nos dice Jorge López, "salta a la vista que la identidad de lo contractual con lo justo es una falacia. Únicamente en circunstancias de real igualdad entre los contratantes, podría tal idea tener alguna verosimilitud" ${ }^{\prime} \mathrm{Y}$ como se esbozó al inicio de este trabajo, dicha igualdad fáctica en una relación laboral simplemente no existe. En cambio, "desde una perspectiva de derecho laboral, la aplicación horizontal de los derechos fundamentales sólo refuerza su construcción dogmática, lejana de la del derecho privado y de la autonomía de la voluntad, ya que su consolidación se ha basado en los límites que se imponen al poder del empleador y, perfectamente, estos límites pueden ser replanteados desde los derechos fundamentales"”.

6. LÓPEZ SANTA MARÍA, Jorge. Los contratos. Parte General. Editorial Jurídica de Chile, Santiago, 1998. Pág. 239.

7. GAMONAL CONTRERAS, Sergio. Trabajo y Derecho. Legal Publishing Chile, Santiago, 2010. Pág. 59.

Facultad de Derecho y Ciencias Sociales - Universidad de Valparaíso - Chile 
La segunda arista anunciada dice relación con determinar si efectivamente existe una relación horizontal entre empleador y trabajador. Sin duda, no podríamos hablar de eficacia vertical, denominación reservada sólo para la relación ciudadano-Estado dada la fuerza de las potestades estatales. Entre trabajador y empleador no hay —o no debería haber - una relación vertical de la intensidad del binomio ciudadano-Estado, pero tampoco existe una plena horizontalidad como entre dos particulares, consecuencia de la especial connotación y particularidades propias de una relación laboral. En este sentido el propio Gamonal señala que "para el derecho del trabajo la aplicación directa de los derechos fundamentales resulta de toda lógica dado los intensos poderes que tiene el empleador sobre el trabajador. Se trata no sólo de poderes económicos sino también jurídicos, que nos permiten sostener que más que una eficacia horizontal entre iguales, es más bien una eficacia diagonal"s.

Cuando hablamos de eficacia diagonal y no de eficacia horizontal, estamos poniendo el acento en el poder del empleador, pues nunca tenemos que olvidar que el contrato de trabajo en nuestro ordenamiento jurídico laboral se define en el artículo 7 del Código del Trabajo, como una "... convención por la cual el empleador y trabajador se obligan recíprocamente, éste a prestar servicios personales bajo dependencia y subordinación del primero, y aquél a pagar por estos servicios una remuneración determinada". El elemento subordinación es de tal importancia que en la práctica define las fronteras sobre cuál trabajo es el protegido por la legislación laboral, e implica que, como nos dice Lanata, "la doctrina la ha entendido (la subordinación) desde el punto de vista jurídico, es decir, se traduce en el poder de mando, dirección, control y fiscalización que ejerce el empleador sobre el trabajador"'. Con este panorama, nadie puede desconocer el poder que posee y ejerce el empleador sobre el trabajador, que en cierto sentido, lo asimila a los poderes estatales. Como bien dice Gamonal, "este poder directivo,

8. $\quad$ Ibídem. Pág. 60.

9. LANATA FUENZALIDA, Gabriela. Contrato Individual de Trabajo. $4^{\mathrm{a}} \mathrm{ed}$. Legal Publishing Chile, Santiago, 2010. Pág. 100.

Revista de Ciencias Sociales - Número 63 (2013) - Universidad de Valparáíso - ISSN 0716-7725-Valparaíso, Chile 
caracterizado como un contenido potestativo propio del derecho del trabajo, alude al derecho que tiene el empleador en orden a dirigir y coordinar el trabajo de sus subordinados" 10 .

En esta excepcional situación en que se encuentran empleador y trabajador, conviene entonces hablar de potestad. Atria la define como "una posición en la que se encuentra una persona cuando mediante una declaración de voluntad puede modificar la posición normativa (es decir, alguna de las normas aplicables) de otra"11. Ahora bien, en ningún caso significa una potestad ilimitada, pues es el propio legislador quien concede esa potestad, por lo tanto se justifica que sea este mismo quien interponga límites y equilibre tales potestades a través del orden público laboral. Así, se trata de un poder limitado y reglado, ya sea por la propia legislación laboral y, si existiera, por la negociación colectiva. También se limita, por los derechos fundamentales del trabajador. En consecuencia, como nos dice Gamonal, "este contenido potestativo tan intenso desequilibra la relación empleador/trabajador, sustrayéndola de una eficacia horizontal y colocándola más bien en el horizonte de una eficacia diagonal de los derechos fundamentales entre particulares"12.

\subsection{Contenido}

El derecho del trabajo y la doctrina laboral, durante mucho tiempo se han dedicado a consagrar y estudiar respectivamente, los derechos propiamente laborales, y en materia de derechos fundamentales, los derechos fundamentales laborales clásicos como el derecho al trabajo o la libertad sindical, pues gozan de una vinculación inmediata con la rama laboral. La doctrina ha llamado a éstos, "derechos fundamentales laborales específicos", y se ha esforzado en estudiar su alcance y vigencia en los distintos ordenamientos jurídicos. Sin embargo, cuando hablamos de Ciudadanía en la Empresa, no nos referimos a estos

10. GAMONAL CONTRERAS, Sergio. Ob. cit. Pág. 60.

11. ATRIA, Fernando. Mercado y Ciudadanía en la Educación. Flandes Indiano, Santiago, 2007. Pág. 51.

12. GAMONAL CONTRERAS, Sergio. Ob. cit. Pág. 63.

Facultad de Derecho y Ciencias Sociales - Universidad de Valparaíso - Chile 
derechos, sino a los que reciben el nombre de "derechos fundamentales laborales inespecíficos", es decir, aquellos que tiene el trabajador como ciudadano.

Dadas las características de la relación laboral, se trata de un escenario donde se pueden cometer abusos por la parte fuerte (empleador) que pueden llegar incluso a vulnerar derechos fundamentales, que en el caso de la Ciudadanía en la Empresa, se refieren a derechos distintos a los derechos fundamentales específicos como la libertad sindical. Se trata como dice Gamonal de "derechos humanos que detenta el trabajador en cuanto persona y ciudadano, derechos civiles que no deberían quedar postergados por el hecho de ser parte de un contrato de trabajo..." 13 .

Lo anterior no quiere decir que estos derechos civiles del trabajador no puedan ser adaptados o restringidos con el objeto de dar cumplimiento a las obligaciones emanadas del contrato de trabajo; así la ley no excluye per se, la posibilidad de limitar los derechos fundamentales de los trabajadores, pero impone la condición de que se trate de limitaciones proporcionales y razonables. Entonces, conveniente es revisar el test de proporcionalidad que propone la doctrina constitucional, que a grandes rasgos, afirma que para limitar derechos fundamentales debemos atender a su: (a) idoneidad, es decir, que la medida debe ser adecuada para los fines que se persigue; (b) necesidad, se trata de un análisis comparativo de la carga que se impone y otras medidas que se pudieren apreciar, y; (c) proporcionalidad en sentido estricto, que es la adecuación entre los medios empleados y los fines perseguidos. Por lo tanto, el empleador debe respetar la esencia de los derechos fundamentales del trabajador.

Para concluir este capítulo, debemos considerar, al respecto de la discusión precedente, que el empleador debe mantener una posición de neutralidad, pues no está obligado con la inserción de un trabajador a la empresa, a sujetar su actividad productiva para favorecer la vigencia de los derechos fundamentales. Al respecto, parafraseando a Baylos, aunque se prohíbe al empleador la coercibilidad de tales libertades, no

13. GAMONAL CONTRERAS, Sergio. Fundamentos de Derecho Laboral. Legal Publishing Chile, Santiago, 2008. Pág. 54

Revista de Ciencias Sociales - Número 63 (2013) - Universidad de Valparáíso - ISSN 0716-7725-Valparáiso, Chile 
se obliga a sujetar la organización productiva, en su estructuración, al ejercicio de derechos fundamentales de su personal ${ }^{14}$. Así, nos dice Gamonal que los derechos fundamentales del trabajador "no constituyen por sí mismos ilimitadas cláusulas de excepción que justifiquen el incumplimiento por parte del trabajador de sus deberes laborales" 15 .

En Chile, la institución de la Ciudadanía en la Empresa nace gracias al desarrollo que al respecto realizó la jurisprudencia administrativa, especialmente la Dirección del Trabajo (DT), y que posteriormente el legislador reconoció en el Código del Trabajo (CdT), llevando a cabo una serie de reformas que consagran disposiciones que reconocen los derechos fundamentales de los trabajadores en el ámbito sustantivo y procesal, estableciendo un procedimiento de tutela de derechos fundamentales, que busca proteger el derecho a la vida, integridad física y psíquica, cuya vulneración tenga relación directa con la actividad laboral; el derecho a la vida privada y la honra; inviolabilidad de las comunicaciones privadas; libertades de creencia y culto; libertad de opinión y libertad de trabajo. Además se consagra un rechazo expreso a conductas discriminatorias. Dicho lo anterior, igualmente hay problemas en este reconocimiento, y críticas atendibles que se pueden formular. Todas las cuestiones anteriores serán, en mayor o menor medida, tratadas en el capítulo siguiente.

\section{Concreción positiva en el derecho chileno de la Ciudadanía en la Empresa}

\subsection{Monumento a la Dirección del Trabajo}

Como esbozamos someramente en los párrafos anteriores, la noción de Ciudadanía en la Empresa se la debemos a la jurisprudencia

administrativa, específicamente, a la labor realizada por la DT, que al

14. BAYLOS, Antonio. Derecho del Trabajo: modelo para armar. Trotta, Madrid, 1991. Pág. 97.

15. GAMONAL CONTRERAS, Sergio. Fundamentos de Derecho Laboral. Ob. cit. Pág. 55.

Facultad de Derecho y Ciencias Sociales - Universidad de Valparaíso - Chile 
respecto ha jugado un rol fundamental para la consagración de los derechos fundamentales inespecíficos en la relación laboral.

La DT ha sido clara en reconocer expresamente los derechos fundamentales del trabajador. A modo ejemplar podemos citar el dictamen 2382/130 de fecha 19 de julio de 2002, donde este Servicio sostiene que "en lo que se refiere a la persona del trabajador, nuestro sistema constitucional, reconoce un conjunto de garantías o derechos fundamentales, no sólo de corte específicamente laboral — por ejemplo: libertad sindicalsino que también el trabajador es titular de derechos fundamentales "inespecíficos" o de la personalidad, que sin ser netamente laborales se aplican a la relación de trabajo en cuanto son inherentes a la condición de ciudadano del trabajador". Más adelante agrega que "los poderes empresariales no puede suponer a priori una relativización o matización del derecho fundamental, más bien, éste es el que actúa como un freno insalvable al ejercicio de tales poderes. Por lo tanto, el problema no tiene sólo una connotación contractual — modalización de la vida dentro de la empresa según las directrices o la organización empresarial —, tiene también un componente que escapa al limitado y circunscrito ámbito del contrato de trabajo para trasladarse a la órbita constitucional, esto es, al ejercicio por parte del trabajador de derechos que trascienden su categorización como trabajador para amoldarse a un plano omnicomprensivo de su personalidad toda. En consecuencia, dicho poder -expresión de las necesidades organizativas o productivas del empresario, pero delimitado jurídicamente en virtud del contrato de trabajo y de la ley-necesariamente ha de verse afectado en alguna medida en aras del respeto pleno de los derechos fundamentales del trabajador" ${ }^{\prime \prime 6}$.

La Dirección de Trabajo ya a fines de la década del 60' se pronunció en sus dictámenes sobre la vigencia e importancia de los derechos fundamentales en el trabajo. A continuación se analizarán algunos de los más importantes en esta materia ${ }^{17}$.

16. Dictamen $\mathrm{N}^{\circ} 2328 / 130$ de 19-07-2002 [en línea] http://www.dt.gob.cl/ legislacion/1611/w3-article-63600.html [consulta: 08 de septiembre de2013].

17. Los dictámenes anteriores a 1995 son revisados en la obra del profesor Sergio Gamonal, "Ciudadanía en la Empresa o los Derechos Fundamentales Inespecíficos". Por lo anterior, se recomienda revisar dicha obra para una mayor profundización al respecto.

Revista de Ciencias Sociales - Número 63 (2013) - Universidad de Valparáíso - ISSN 0716-7725-Valparáiso, Chile 
a) Derecho a la honra y la vida privada ${ }^{18}$

Uno de los primeros dictámenes que constata la vulneración de estos derechos es el dictamen $\mathrm{N}^{\circ} 3965$ del 05 de junio de 1969. En dicho dictamen la DT sostiene que atenta contra la dignidad de la persona y, en ese caso, del trabajador, someterlo a controles de revisión una vez concluida la jornada laboral. En este mismo tenor, la DT sigue esta línea en el dictamen $\mathrm{N}^{\circ} 4606$ del 15 de octubre de 1976, donde señala que la revisión de las carteras de las trabajadoras del Hotel Crillón, atenta contra su dignidad.

Siguiendo con dictámenes históricos, la DT en lo dictámenes $\mathrm{N}^{\circ} 338$ y N 2449 de 26 de enero de 1978 y del 04 de noviembre de 1982 respectivamente, de manera expresa reconoce que los actos de revisión y control personal a trabajadores atenta contra su vida privada y dignidad. Así la DT en el primer dictamen señala que "esta Dirección ha sostenido reiterada y categóricamente que la revisión de especies a los trabajadores atenta contra su dignidad y honra, derechos consagrados y garantizados por precepto de rango constitucional [...]"19. En el segundo dictamen en comento, la DT sostiene que "la revisión de efectos personales y la inspección corporal de los trabajadores atenta contra su dignidad y honra, toda vez que con ello se estaría infringiendo el artículo $19 n^{\circ} 4$ de la Constitución Política de la República [...]"20.

No obstante lo anterior, según la propia DT, nada prohíbe que el empleador pueda adoptar medidas de revisión, siempre y cuando éstas no atenten contra la dignidad y honra de los trabajadores. Al respecto la DT en su dictamen $\mathrm{N}^{\circ} 252$ del 13 de enero de 1989 sostiene que, "sin embargo, es necesario destacar que por existir también otros derechos del mismo rango constitucional, de igual e incluso superior

18. Artículo $19 \mathrm{n}^{\circ} 4$ de la Constitución Política de la República (La Constitución asegura a todas las personas): El respeto y protección a la vida privada y a la honra de la persona y su familia.

19. GAMONAL CONTRERAS, Sergio. Ciudadanía en la Empresa. Ob. cit. Pág. 27.

20. Ídem.

Facultad de Derecho y Ciencias Sociales - Universidad de Valparaíso - Chile 
jerarquía, que podrían verse eventualmente lesionados, se hace menester precisar el alcance de lo resuelto a fin de que pueda garantizarse adecuadamente su ejercicio con la práctica de medidas preventivas o de resguardo ejercidas por las empresas.

En efecto, en opinión de este Servicio, de una oportuna prevención puede derivar una eficaz protección de valores trascendentes, tales como los implícitos en el derecho a la vida e integridad física de las personas, derecho a la salud y el derecho de propiedad, consagrados en los $N^{o} 1,9$ y 24 del artículo 19 de la Carta Fundamental, los que, sin duda, requieren de medidas cautelares para asegurar su pleno ejercicio.

En base a lo anteriormente expuesto, se estima que encontraría plena justificación que la empresa adopte medidas de revisión, siempre y cuando ellas estén destinadas a evitar que se atente contra los derechos ya enunciados, y que su práctica no viole o atente contra otros derechos como serían la honra y dignidad de las personas"21.

La DT en dictámenes posteriores profundiza su línea argumental a tal punto que es el mismo Servicio el que entrega las directrices y pautas de cómo deben ser las herramientas o medios de revisión y control que la empresa puede emplear. Así la DT en su dictamen $\mathrm{N}^{\circ} 4841$ del 15 de septiembre de 1993 sostiene que es "necesario que tales medidas se integren a sistemas que sean compatibles con el respeto a la honra y dignidad de los trabajadores y en razón de este objetivo se requiere que los sistemas de prevención sean técnicos y despersonalizados, y que, por ende, se apliquen mediantes mecanismos automáticos o de sorteo, que eviten que su operación o funcionamiento se produzca frente a presunciones de actos o conductas ilícitas o concretas"22.

En 1995, en el dictamen $\mathrm{N}^{\circ} 8273 / 337$ del 19 de diciembre de 1995, la DT en su facultad interpretativa, establece las características que deben reunir las medidas de control para asegurar el respeto y promoción de la dignidad y honra de los trabajadores. El profesor Caamaño da cuenta de la importancia de este dictamen, al sostener

21. GAMONAL CONTRERAS, Sergio. Ciudadanía en la Empresa. Ob. cit. Pág. 29.

22. Ibídem. Pág. 33.

Revista de Ciencias Sociales - Número 63 (2013) - Universidad de Valparáíso - ISSN 0716-7725-Valparáiso, Chile 
que mediante éste se pretende "consolidar los criterios aplicables para validar la implementación de medidas de control y en el que se resolvió que las medidas de este tipo que la ley autoriza, e incluso impone, al obligar a ciertos empleadores a dictar un Reglamento Interno de higiene y Seguridad, de conformidad con los artículos 153 y 154 del Código del Trabajo"23. La DT, enseguida expone los requisitos que estas medidas de control deben considerar, y obliga que los Reglamentos Internos de las empresas tomen en cuenta dichas características, a saber:

“a) Las medidas de revisión y control de las personas, de sus efectos privados o de sus casilleros, al importar un límite a la privacidad de las personas, debe necesariamente incorporarse en el texto normativo que la ley establece para el efecto, esto es, el Reglamento Interno de Higiene y Seguridad de la empresa, dictado en conformidad a la ley.

b) Las medidas de revisión y control deben ser idóneas a los objetivos perseguidos como son el mantenimiento del orden, la higiene y la seguridad de la persona y sus trabajadores, no debiendo importar actos ilegales o arbitrarios por parte del empleador, según lo señala la Constitución en su artículo 20, como por ejemplo la selección discrecional de las personas a revisar o la implementación de medidas extrañas e inconducentes a los objetivos ya señalados.

c) Las medidas, además, no deben tener un carácter prepolicial, investigatorio o represivo frente a supuestos o presuntos hechos ilícitos dentro de la empresa, sino un carácter puramente preventivo y despersonalizado, siendo requisito "sine qua non" para la legalidad de estas medidas revisión y control, que sean operadas a través de un mecanismo o sistema de selección, cuyas características fundamentales son la universalidad y la despersonalización de las revisiones" ${ }^{24}$.

b) Inviolabilidad del hogar y de toda forma de comunicación privada $^{25}$.

23. CAAMAÑO ROJO, Eduardo. Ob. cit. Pág. 37.

24. Dictamen $\mathrm{N}^{\circ} 8273 / 337$ de 19-12-1995[en línea] http://www.dt.gob.cl/ legislacion/1611/w3-article-89123.html [consulta: 08 de septiembre de 2013].

25. Artículo 19 n $^{\circ} 5$ de la Constitución Política de la República.

Facultad de Derecho y Ciencias Sociales - Universidad de Valparaíso - Chile 
También es importante destacar, en este breve análisis jurisprudencial, lo que ha sostenido la DT respecto a este derecho, pues el empleador cuenta — dentro de su poder de administración — con atribuciones para regular las condiciones, frecuencia y oportunidad de uso de los correos electrónicos de la empresa, pero en ningún caso podrá tener acceso a la correspondencia electrónica privada enviada y recibida por los trabajadores ${ }^{26}$. En este sentido la DT ha sostenido en su dictamen $\mathrm{N}^{\circ} 260 / 19$ de fecha 24 de enero de 2002 que "será entonces el empleador quién podrá tomar la iniciativa para formalizar esta normativa interna de la empresa y, en el ámbito de sus facultades de administración, podrá también incorporar preceptos a este reglamento con el fin específico de regular, limitar o restringir el empleo de los correos electrónicos por los dependientes, todo lo cual no obsta — como se ha dicho_que "El delegado del personal, cualquier trabajador, o las organizaciones sindicales de la empresa respectiva" (artículo 153 inciso $3^{\circ}$ del Código del Trabajo), pueda impugnar de ilegalidad estas normas ante este Servicio. Se reitera, esta regulación podrá recaer en el uso del correo electrónico, no en la garantía constitucional de inviolabilidad de la comunicación privada".

Posteriormente agrega que "podrá regularse radicalmente el uso del correo electrónico por alguna de las formas descritas precedentemente, en términos tales que todo envío del personal se efectúe con copia a alguna Gerencia o Unidad de la empresa, envío que de esta forma perderá — en el instante - su condición de comunicación privada, regulación que sin embargo no es practicable en el caso de la recepción de correspondencia electrónica, y por tanto, en este aspecto, esta modalidad de comunicación conserva siempre su carácter privada, como asimismo, permanecerá plenamente amparada por la referida y correspondiente garantía constitucional"27.

En el siguiente capítulo veremos cómo el legislador recoge la jurisprudencia de la DT y consagra en nuestro CdT las ideas que se representan en la institución de la Ciudadanía en la Empresa.

\section{CAAMAÑO ROJO, Eduardo. Ob. cit. Pág. 41.}

27. Dictamen $\mathrm{N}^{\circ} 260 / 19$ de 24-01-2002 [en línea] http://www.dt.gob.cl/legislacion/ 1611/w3-article-63171.html [consulta: 08 de septiembre de 2013].

Revista de Ciencias Sociales - Número 63 (2013) - Universidad de Valparáíso - ISSN 0716-7725-Valparaíso, Chile 


\subsection{El legislador no se quiso quedar atrás}

El punto de partida de este análisis es sin lugar a dudas la Ley $19.759^{28}$ donde el legislador reconoce expresamente la eficacia horizontal de los derechos fundamentales en la relación laboral. Esta ley agrega el actual inciso primero del artículo 5 del CdT que reza en el siguiente tenor: "El ejercicio de las facultades que la ley le reconoce al empleador, tiene como límite el respeto a las garantías constitucionales de los trabajadores, en especial cuando pudiera afectar la intimidad, la vida privada o la honra de éstos" ${ }^{\prime 2}$. Se establece así, una limitación a los poderes de control o dirección que la legislación le reconoce a los empleadores, pues nunca podrían significar una lesión o vulneración de derechos fundamentales, haciendo especial análisis a la intimidad, vida privada y honra de los trabajadores.

No obstante la opción que toma el legislador de consagrar positivamente el efecto horizontal de los derechos fundamentales y no esperar, como sostiene Ugarte, una decisión de la justicia constitucional siguiendo el modelo europeo, como expresa Caamaño "puede contribuir a generar un cambio cultural en los actores sociales, en vistas a internalizar, en la práctica, la validez de los derechos fundamentales en el plano de las relaciones laborales. Desde esta perspectiva, lo importante y, a la vez, el principal mérito de esta reforma legal, es que ahora los trabajadores "conocen" gracias a esta disposición que los derechos fundamentales que detentan por su condición de personas no pierden vigencia o sentido al interior de la empresa, como asimismo, que éstos constituyen un límite al poder empresarial. Además, destaca la ubicación de este precepto, por sobre la irrenunciabilidad de los derechos laborales, con lo que queda clara la jerarquía superior y la eficacia de los derechos fundamentales por sobre los derechos estrictamente laborales" ${ }^{\prime 30}$.

28. Ley $\mathrm{N}^{\circ} 19.759$ publicada en el Diario Oficial el 5 de octubre de 2001.

29. En este sentido se recomienda ver el dictamen $\mathrm{N}^{\circ}$ 2856/162 de 30-08-2002, Trabajo.

que fija el sentido y alcance del inciso primero del artículo 5 del Código del

30. CAAMAÑO ROJO, Eduardo. Ob. cit. Pág. 32.

Facultad de Derecho y Ciencias Sociales - Universidad de Valparaíso - Chile 
También es pertinente hacer un comentario respecto a otra modificación importante en esta materia introducida por la ley 19.759, en lo relativo al nuevo inciso final del artículo 154 del CdT, que nos señala que "[...] en general, toda medida de control, sólo podrá efectuarse por medios idóneos y concordantes con la naturaleza de la relación laboral y, en todo caso, su aplicación deberá ser general, garantizándose la impersonalidad de la medida, para respetar la dignidad del trabajador". Con esta disposición el legislador no hace más que recoger la jurisprudencia ya consolidada de la DT y que hemos tenido oportunidad de comentar anteriormente.

Otra enmienda importante en esta materia es la nueva redacción del artículo 2 inciso 2, frase 1, del CdT, en virtud del cual: "Las relaciones laborales deberán siempre fundarse en un trato compatible con la dignidad de la persona". Además en este mismo artículo, se sostiene que son contrarios a los principios laborales los actos de discriminación, ya sea por raza, color, sexo, edad, estado civil, etc.

Todas estas normas vienen a contribuir a que se abandone la idea clásica del patrón todopoderoso y del trabajador obediente. Sin la existencia de límites, las consecuencias eran nefastas para los trabajadores, pues se pasaba por alto sus derechos fundamentales. No deja de llamar la atención que sea la ley la que venga a establecer expresamente que los trabajadores gozan plenamente de derechos fundamentales, pues estos no se pierden en una relación laboral, ya que, si bien la ley debe establecer un piso mínimo, una sociedad medianamente civilizada y democrática, no tendría dudas de aquello. Ahora bien, lo deseable sería que a través de la autotutela colectiva los trabajadores y empleadores puedan acordar condiciones de trabajo al interior de la empresa que no pongan ni siquiera en discusión que el trabajador es ciudadano, tanto dentro como fuera de la empresa.

\section{Reflexiones finales: nos olvidamos de lo fundamental}

A lo largo de este trabajo, se ha pretendido poner de manifiesto el reconocimiento en nuestro ordenamiento jurídico laboral de los derechos fundamentales del trabajador, dejando atrás la idea de un derecho laboral restringido sólo a los derechos propiamente laborales, y

Revista de Ciencias Sociales - Número 63 (2013) - Universidad de Valparáíso - ISSN 0716-7725-Valparaíso, Chile 
expandiéndose a reconocer y tutelar los llamados derechos fundamentales inespecíficos de los trabajadores y trabajadoras.

Sin lugar a dudas, nadie sensato podría negar los beneficios y/o ventajas que trae consigo un reconocimiento expreso de la noción de Ciudadanía en la Empresa en nuestro derecho, pues la jurisprudencia y las modificaciones legales acá analizadas dan muestra de una mayor protección al trabajador en cuanto éste no puede ver lesionados sus derechos fundamentales en su actividad laboral. Sin embargo, reconociendo todo lo positivo que nos entrega dicho reconocimiento, se puede igualmente expresar algunas críticas, sobre todo a la tutela de derechos fundamentales del trabajador.

Si bien el procedimiento de tutela jurisdiccional de los derechos fundamentales del trabajador no es el objeto de este estudio, si podemos señalar a grandes rasgos que, por ejemplo, nos enfrentamos a la inexistencia de un procedimiento especial y propio de tutela de estos derechos, pues como nos señala Ugarte, "en estricto rigor, no existe un tal procedimiento de tutela de derechos fundamentales, sino una cosa ligeramente distinta: el procedimiento de aplicación general con reglas especiales para el caso de vulneración de derechos fundamentales" ${ }^{\prime 31}$.

En este mismo sentido, también se puede revisar con cuidado y escepticismo el "bien jurídico" protegido por este procedimiento de tutela, pues el artículo 485 del CdT, establece sin ninguna justificación una lista taxativa de derechos fundamentales que están cubiertos por esta acción. Al respecto, Ugarte nos señala que, "en rigor, el bien jurídico protegido por la acción de tutela no corresponde a los derechos fundamentales del trabajador a secas. Ni siquiera los derechos fundamentales previstos expresamente por el texto constitucional en el ya citado artículo 19. Lo protegido son los derechos fundamentales del trabajador previstos expresamente en la "lista" contemplada en el artículo 485 del Código del Trabajo"32.

Por lo tanto, al revisar el listado que nos ofrece el artículo 485, inciso primero del $\mathrm{CdT}$, nos damos cuenta que el procedimiento de

31. UGARTE CATALDO, José Luis. Tutela de Derechos Fundamentales del Trabajador. Legal Publishing Chile, Santiago, 2009. Pág. 24

32. Ídem. Pág. 33.

Facultad de Derecho y Ciencias Sociales - Universidad de Valparaíso - Chile 
tutela se aplica "respecto de las cuestiones suscitadas en la elación laboral por aplicación de las normas laborales, que afecten los derechos fundamentales de los trabajadores, entendiéndose por éstos los consagrados en la Constitución Política de la República en su artículo 19, números $1^{\circ}$, inciso primero, siempre que su vulneración sea consecuencia directa de actos ocurridos en la relación laboral, $4^{\circ}, 5^{\circ}$, en lo relativo a la inviolabilidad de toda forma de comunicación privada, $6^{\circ}$, inciso primero, $12^{\circ}$ inciso primero, y $16^{\circ}$, en lo relativo a la libertad de trabajo, al derecho a su libre elección y a lo establecido en su inciso cuarto, cuando aquellos derechos resulten lesionados en el ejercicio de las facultades del empleador".

En resumen el procedimiento sólo protege los siguientes derechos fundamentales: derecho a la vida; derecho a la integridad física y síquica; derecho a la intimidad y el respeto a la vida privada; derecho al honor; derecho a la inviolabilidad de toda forma de comunicación privada; derecho a la libertad de conciencia, la manifestación de las creencias y el libre ejercicio de todos los cultos; libertad de expresión, opinión e información sin censura previa; y, libertad de trabajo y de contratación laboral. Además se reconoce, a través de este procedimiento, la protección del derecho a no ser discriminado (artículo 2 del CdT), pero se excluye de este procedimiento la discriminación efectuadas por vías de las ofertas de empleo, así como nos dice Ugarte y las conductas discriminatorias pre-ocupacionales ${ }^{33}$. Con todo lo anterior, la crítica más fuerte es la consagración de una lista taxativa de derechos protegidos por este procedimiento, pues lo correcto habría sido reconocer, al menos, todo el catálogo de derechos fundamentales del artículo 19 de la CPR, pues, ¿acaso en un relación laboral no se puede vulnerar el derecho a la salud, a la educación, a vivir en un medio ambiente libre de contaminación, o el derecho de propiedad tan bien considerado por el constituyente? Claro que sí pueden ser objetos de lesiones, por lo tanto se debería ampliar el catálogo del artículo 485 del CdT.

Para finalizar, también podemos expresar, que sería conveniente que con el mismo entusiasmo que nuestro derecho reconoce los derechos fundamentales inespecíficos de los trabajadores, ya sea a través de la jurisprudencia de la DT o de las modificaciones legales introducidas

33. Ídem Pág. 35.

Revista de Ciencias Sociales - Número 63 (2013) - Universidad de Valparáíso - ISSN 0716-7725-Valparaíso, Chile 
por el legislador, pueda consagrar, promover y reconocer la plena vigencia de derechos fundamentales específicos, que hoy en nuestro país se vulneran abiertamente, como la libertad sindical, reconociendo dentro de ésta el derecho a sindicación (cuestión relativamente reconocida en nuestro país), la negociación colectiva y el derecho a huelga, ambos muy por debajo de los estándares internacionales de la OIT, ergo, vulnerando abiertamente derechos fundamentales y tratados internacionales.

En el mismo sentido del párrafo anterior, el profesor Gamonal nos dice, que "la ciudadanía en la empresa es un gran aporte, pero puede revestir un peligro si la cultura jurídica imperante llega a pretender que por la sola operativa de los derechos fundamentales las técnicas tradicionales de tutela del trabajador queden superfluas u obsoletas, o que puedan llegar a reemplazarse los derechos laborales específicos, como la libertad sindical o la justa retribución" 34 .

Esperemos, tal vez con un poco de ingenuidad, que el entusiasmo que embargó a nuestro legislador, alcance también para que pueda reconocer sin miedos, derechos fundamentales propios de los trabajadores que deberían ser ampliamente aceptados, respetados y promovidos en cualquier sociedad democrática que aspira a ser una nación desarrollada.

\section{Bibliografía}

ATRIA, Fernando. Mercado y Ciudadanía en la Educación. Santiago, Flandes Indiano, 2007.

BAYLOS, Antonio. Derecho del Trabajo: modelo para armar. Madrid, Trotta, 1991.

CAAMAÑO ROJO, Eduardo. La eficacia de los derechos fundamentales en las relaciones laborales y su reconocimiento por la Dirección del Trabajo. Revista de Derecho de la Pontificia Universidad Católica de Valparaíso. 27 (I semestre). 2006.

34. GAMONAL CONTRERAS, Sergio. Ciudadanía en la Empresa. Ob. cit. Pág. 74.

Facultad de Derecho y Ciencias Sociales - Universidad de Valparaíso - Chile 
GAMONAL CONTRERAS, Sergio. Ciudadanía en la Empresa o Derechos Fundamentales Inespecíficos. Santiago, Fundación de la Cultura Universitaria, 2004.

GAMONAL CONTRERAS, Sergio. Fundamentos de Derecho Laboral. Santiago, Legal Publishing Chile, 2008.

GAMONAL CONTRERAS, Sergio. Trabajo y Derecho. Santiago, Legal Publishing Chile, 2010.

LANATA FUENZALIDA, Gabriela. Contrato Individual de Trabajo. $4^{a}$ ed. Santiago, Legal Publishing Chile, 2010.

LÓPEZ SANTA MARÍA, Jorge. Los contratos. Parte General. Santiago, Editorial Jurídica de Chile, 1998.

SUPIOT, Alain. Crítica del Derecho del Trabajo. Madrid, Ministerio del Trabajo y Asuntos Sociales, 1996.

UGARTE CATALDO, José Luis. El nuevo Derecho del Trabajo. Santiago, LexisNexis, 2007.

UGARTE CATALDO, José Luis. Tutela de Derechos Fundamentales del Trabajador. Santiago, Legal Publishing Chile, 2009. 